\title{
EVALUATION OF THE IMPACT OF ATMOSPHERIC PRESSURE IN DIFFERENT SEASONS ON BLOOD PRESSURE IN PATIENTS WITH ARTERIAL HYPERTENSION
}

\author{
MAREK KAMIŃSKI ${ }^{1}$, URSZULA I. CIEŚLIK-GUERRA ${ }^{2}$, RAFAŁ KOTAS ${ }^{1}$, PIOTR MAZUR ${ }^{1}$, WITOLD MARAŃDA ${ }^{1}$, \\ MACIEJ PIOTROWICZ1 ${ }^{1}$ BARTOSZ SAKOWICZ ${ }^{1}$, ANDRZEJ NAPIERALSKI ${ }^{1}$, EWA TRZOS ${ }^{2}$, \\ BARBARA UZNAŃSKA-LOCH², TOMASZ RECHCIŃSKI², and MAŁGORZATA KURPESA ${ }^{2}$
}

${ }^{1}$ Lodz University of Technology, Łódź, Poland

Department of Microelectronics and Computer Science

${ }^{2}$ Medical University of Lodz, Łódź, Poland

Department of Cardiology

\begin{abstract}
Objectives: Atmospheric pressure is the most objective weather factor because regardless of if outdoors or indoors it affects all objects in the same way. The majority of previous studies have used the average daily values of atmospheric pressure in a bioclimatic analysis and have found no correlation with blood pressure changes. The main objective of our research was to assess the relationship between atmospheric pressure recorded with a frequency of 1 measurement per minute and the results of 24-h blood pressure monitoring in patients with treated hypertension in different seasons in the moderate climate of the City of Łódź (Poland). Material and Methods: The study group consisted of 1662 patients, divided into 2 equal groups (due to a lower and higher average value of atmospheric pressure). Comparisons between blood pressure values in the 2 groups were performed using the Mann-Whitney U test. Results: We observed a significant difference in blood pressure recorded during the lower and higher range of atmospheric pressure: on the days of the spring months systolic $(\mathrm{p}=0.043)$ and diastolic $(\mathrm{p}=0.005)$ blood pressure, and at nights of the winter months systolic blood pressure $(p=0.013)$. Conclusions: A significant inverse relationship between atmospheric pressure and blood pressure during the spring days and, only for systolic blood pressure, during winter nights was observed. Int J Occup Med Environ Health 2016;29(5):783-792
\end{abstract}

Key words:

Arterial hypertension, Atmospheric pressure, Ambulatory blood pressure monitoring, ABPM, Impact of weather on health, Weather

\footnotetext{
The project was financed with the help of the National Science Center (Kraków, Poland) funds (DEC-2011/03/B/ST6/03454) granted to M. Kamiński, Ph.D., R. Kotas, Ph.D., P. Mazur, M.Sc., B. Sakowicz, Ph.D., and Prof. A. Napieralski, grant manager: Marek Kamiński, Ph.D. This publication was also supported by the Young Medical Scientists Grant from Medical University of Lodz (No. 502-03/1-049-01/502-14-058) granted to U.I. Cieślik-Guerra, M.D. Grant manager: Urszula Izabela Cieślik-Guerra, M.D.

Received: December 16, 2014. Accepted: October 5, 2015.

Corresponding author: U.I. Cieślik-Guerra, Medical University of Lodz, Department of Cardiology, Biegański Hospital, Kniaziewicza 1/5, 91-347 Łódź, Poland (e-mail: cieursz@wp.pl).
} 


\section{INTRODUCTION}

The idea of climate impact on human health came up already in the antiquity in the works of Hippocrates [1]. In the Middle Ages, the "mighty air" was identified with epidemics which ravaged Europe. Basic understanding of bioclimatology originated in the period of Enlightenment. But it was only technological and industrial revolution that allowed continuous recording of weather and life parameters, which enabled assessment of their mutual relationship.

Thanks to the progress of civilization, people are rarely exposed to extreme weather factors such as: rainfall, sunshine, wind, temperature and so on. Atmospheric pressure (AP) in the bio-synoptic analysis seems to be the most objective meteorological factor having the same influence on us - indoors and outdoors. Distribution of air pressure systems (high and low AP) influences air movement, which shapes the climate. Some of the studies have confirmed that the flow of specific air masses is correlated with changes in well-being and the accompanying changes in blood pressure (BP) [2-5].

Patients with chronic diseases are more liable to weather changes compared to healthy individuals [6]. In the case of patients with hypertension, even small fluctuations in BP influenced by weather can potentially result in serious neurological and cardiovascular complications. It is suggested that the decrease in AP increases BP via the sympathetic nervous system and the immune system [7].

Following the premises of previous clinical trials and problems reported by patients with stabilization of BP on certain days and times of the year, one objective was set. The main objective of our research was to assess the influence of AP on the results of 24-h ambulatory blood pressure monitoring (ABPM) in patients with hypertension in different seasons in transitional temperate climate of the City of Łódź (Poland).

In our work, we decided to use a continuous measurement of AP and take into account short-term AP fluctuations. Similarly to other works, due to distinct seasonality of a temperate climate, the assessment was planned in individual seasons. Due to the high prevalence of hypertension problem and its complications in Poland, a study group of patients with hypertension was selected, which had ABPM performed in our center.

This study is the first study in Poland, which has evaluated the effect of AP on BP in patients with arterial hypertension on such a scale. The proposed method allowed calculation of the correlation between atmospheric and blood pressure.

\section{MATERIAL AND METHODS}

Averaged atmospheric pressure was determined for each reading of the ABPM parameters. Weather parameters were calculated as the average of the records from the weather station for a period of $5 \mathrm{~min}$ - in the range from $2.5 \mathrm{~min}$ before reading the ABPM parameters to $2.5 \mathrm{~min}$ after reading this parameter.

\section{Patients}

The study used ABPM records of patients of the Cardiology Clinic, Biegański Hospital in Łódź, which were performed in the Laboratory of Noninvasive Electrocardiology, Department of Cardiology, Medical University of Lodz (51 $\left.48^{\prime} 4^{\prime \prime} \mathrm{N}, 19^{\circ} 26^{\prime} 14^{\prime \prime} \mathrm{E}\right)$ at an altitude of $214 \mathrm{~m}$ above sea level. Inclusion criteria were:

- diagnosed and treated hypertension,

- age $>18$ years,

- $80 \%$ of technically correct BP measurements during monitoring (every hour monitoring: at least 2 valid measurements during the day and at least 1 at night), - place of residence in Łódź.

Hypertension was diagnosed based on the information in the documentation and antihypertensive therapy according to the latest guidelines [8]. Exclusion criteria were:

- lack of a consent to participate in the study,

- recording pressure during night shift work,

- work at heights, 
- place of residence at a distance greater than $30 \mathrm{~km}$ from the metrological station,

- low quality of the recording,

- recognized atrial fibrillation.

We excluded a total of 124 records because of: age $<18$ years (1 patient), low quality of ABPM recording (3 patients), missing records from meteorological station (3 patients), too small a number of ABPM samples during the day or night (27 patients), place of residence (40 patients), patients working during nighthours (10 patients) and atrial fibrillation (40 patients). Finally, the study included 1662 records from between January 1, 2009 and December 31, 2012.

All the patients gave their written informed consent to participate in the study and agreed to the use of their records for scientific purposes. The study protocol was approved by the Bioethical Commission of the Medical University of Lodz.

\section{Measurement of blood pressure}

In order to monitor BP, SpaceLabs 90207 recorders (Spacelabs, Redmond, WA, USA), validated by the British Hypertension Society, were used [9]. The data were collected during the day (6:00 a.m. - 11:00 p.m.) at intervals of $20 \mathrm{~min}$ and during the night (11:00 p.m. - 6:00 a.m.) every $30 \mathrm{~min}$. During the examination, the patients carried on their daily activities. After completion of the monitoring and storing the results in the system, the data have not been edited.

The following pressure values for the properly controlled hypertension have been assumed: average pressure during $24 \mathrm{~h}-130 / 80 \mathrm{~mm} \mathrm{Hg}$, during the day - 135/85 mm Hg, during the night - 120/70 mm Hg [8]. Normal nocturnal lowering of the BP (the so-called dipping) was assumed as a decrease in the mean arterial BP at night by 10-20\% relative to the average pressure during the day. The patients defined as extreme-dippers were those with a nocturnal decrease in the mean arterial pressure exceeding $20 \%$.
When average pressure drop was $<10 \%$, the patients were defined as non-dippers. The fourth category of inverse-dippers was introduced for the patients whose mean arterial BP at night was higher than that during the day.

\section{Weather station}

LB-741 meteorological station (LAB-EL, Reguły, Poland) is located on the roof of the Department of Microelectronics and Computer Science, Lodz University of Technology (51'44'46”N, 19²7'20"E) at an altitude of $211 \mathrm{~m}$ above sea level. Measurement of the absolute (actual) AP was taken with the barometer LB-716AP (LAB-EL). The device has a calibration certificate [10] of the Laboratory of the Air Force Institute of Technology in Warszawa and the Calibration Laboratory LAB-EL.

The station is used for online monitoring of several meteorological parameters: temperature and relative humidity (thermometer-hygrometer LB-710R (LAB-EL), with temperature sensor Pt-1000), horizontal component of wind speed (meter LB-746 (LAB-EL)), intensity of solar radiation (meter LB-900 (LAB-EL), equipped with a microprocessor-based measuring system, and external pyranometer CM-21 (Kipp \& Zonen, Delft, the Netherlands)). Calibration is performed individually for each device and stored in nonvolatile memory, and the measurement results are sent in digital form to the master unit. Measurements are taken every minute.

\section{Characteristics of topography and climate of the City of Łódź}

Lódź is located in central Poland, at an altitude of 162$278 \mathrm{~m}$. The climate of Łódź region is very transient because of the location and lowland terrain. Łódź region can be assigned to the areas with less diverse weather (low stimulogenic) in the relation to the whole country. Annually, the monthly average AP values differ slightly. The largest pressure fluctuations occur from November to March, and the lowest - in the summer [11,12]. 


\section{Statistical analysis}

All calculations were performed using the Matlab software R2013a (The MathWorks, Natick, MA, USA). The minimum level of statistical significance $(p)$ for all the analyses was assumed as $<0.05$.

\section{Analysis of weather parameters influence on blood pressure}

The analysis included tests of the influence of AP on BP in a broader context than a sole evaluation of a linear correlation. We used methods proposed by Modesti et al. [13]. Due to the weather parameter values, days/nights were divided into two equal groups. The first group (A) included $50 \%$ of the days/nights with a lower average value of AP, and the second (B) $-50 \%$ of the days/nights with a higher average AP. The BP data were divided into two groups based on the days/nights distribution according to the average value of the AP. The first group included BP data recorded during the time of lower $\mathrm{AP}$, and the second group - BP data recorded during the time of higher AP. For each group of patients, the mean \pm standard deviation $(\mathrm{M} \pm \mathrm{SD})$ of $\mathrm{BP}$ was calculated.

Separate statistics were made for nights and days. Period from 12:00 a.m. to 6:00 a.m. was considered as a night, and period from 8:00 a.m. to 8:00 p.m. as a day.

The analyses were made for all the seasons together and separately, just as follows:

- winter: December, January, and February;

- spring: March, April, and May;

- summer: June, July, and August;

- autumn: September, October, and November.

Atmospheric pressure was calculated as an arithmetic mean for the entire period of observation (day or night). Comparisons between the groups were performed using the Mann-Whitney U test because most of the dependent variables did not meet the assumption of normality. For normally distributed variables (heart rate for a period of four years and for the spring), the Student's t-test was used.

\section{RESULTS}

\section{Patients}

The study included 1662 patients aged 18-90 years. All the patients were receiving antihypertensive treatment. Table 1 presents description of the patients and the ABPM parameters. Women dominated in the group of the oldest patients. Although the percentage of patients with a wellcontrolled BP in this group was significantly higher than in other groups, the percentage of patients with normal decrease of BP during the night was the smallest. Phenomenon of an inverted profile of the circadian BP in this group was observed significantly more often than in the younger patients.

\section{Influence of weather parameters on blood pressure}

During the entire year, at the time of lower AP the recorded BP was higher, and opposite - at the time of higher AP - BP was lower. The influence of AP seems to be significant with regard to systolic and diastolic BP in the spring days and to systolic BP - in the winter nights (Table 2). Only in few cases, the two groups differed at the level of statistical significance.

\section{DISCUSSION}

We observed a significant inverse relationship between AP and BP during the spring days and only for systolic BP during winter nights.

This study is the first in Poland that has evaluated the effect of AP on BP in patients with arterial hypertension on such a scale. The proposed method of weather data analysis provides a comprehensive analysis of the influence of the daily AP variations in individual seasons on $\mathrm{BP}$ for each patient.

The influence of AP on human body is not as obvious as the influence of temperature discussed in many works [13-16]. In Poland, in the transitional moderate climate, most patients stay in heated rooms in winter and in the summer more and more patients stay in 
Table 1. Characteristics of the study population with arterial hypertension along with ambulatory blood pressure monitoring (ABPM) parameters according to the patients age

\begin{tabular}{|c|c|c|c|c|}
\hline \multirow{2}{*}{ Variable } & \multicolumn{4}{|c|}{ Patients } \\
\hline & total & $<50$ years & $50-65$ years & $>65$ years \\
\hline \multicolumn{5}{|l|}{$\operatorname{Sex}[n(\%)]$} \\
\hline men & $855(51.4)$ & $183(65.4)$ & $400(57.6)$ & $272(39.5)$ \\
\hline women & $807(48.6)$ & $97(34.6)$ & $294(42.4)^{c}$ & $416(60.5)^{c, d}$ \\
\hline total & $1662(100.0)$ & $280(16.8)$ & $694(41.8)$ & $688(41.4)$ \\
\hline Age $^{\text {a }}$ years] $(\mathrm{M} \pm \mathrm{SD})$ & $61.4 \pm 14.6$ & $37.0 \pm 9.7$ & $58.4 \pm 4.4$ & $74.4 \pm 5.5$ \\
\hline \multicolumn{5}{|c|}{ Blood pressure $[\mathrm{mm} \mathrm{Hg}](\mathrm{M} \pm \mathrm{SD})$} \\
\hline systolic & $118.8 \pm 13.2$ & $118.8 \pm 12.4$ & $119.0 \pm 13.5$ & $118.5 \pm 12.7$ \\
\hline diastolic & $67.0 \pm 9.0$ & $68.9 \pm 9.2$ & $68.5 \pm 9.1$ & $64.5 \pm 8.1$ \\
\hline Heart rate $[\mathrm{bpm}](\mathrm{M} \pm \mathrm{SD})$ & $67.8 \pm 10.0$ & $70.2 \pm 10.3$ & $68.1 \pm 10.4$ & $66.3 \pm 9.0$ \\
\hline \multicolumn{5}{|c|}{ Dipping in blood pressure $[\mathrm{n}(\%)]$} \\
\hline dippers & $565(34.0)$ & $117(41.8)$ & $246(35.4)$ & $202(29.5)^{c, d}$ \\
\hline extreme-dippers & $58(3.5)$ & $5(1.8)$ & $30(4.3)$ & $23(3.3)$ \\
\hline non-dippers & $767(46.1)$ & $123(43.9)$ & $330(47.6)$ & $314(45.6)$ \\
\hline inverse-dippers & $272(16.4)$ & $35(12.5)$ & $88(12.7)$ & $149(21.6)^{c, d}$ \\
\hline \multicolumn{5}{|c|}{ Blood pressure proper control ${ }^{\mathrm{b}}[\mathrm{n}(\%)]$} \\
\hline 24-h & $1435(86.3)$ & $222(79.3)$ & $583(84.0)$ & $630(91.6)^{c, d}$ \\
\hline daytime & $1510(90.8)$ & $240(85.7)$ & $616(88.8)$ & $654(95.0)^{\mathrm{c}, \mathrm{d}}$ \\
\hline nighttime & $1299(78.2)$ & $212(75.7)$ & $519(74.8)$ & $568(82.6)^{\mathrm{c}, \mathrm{d}}$ \\
\hline
\end{tabular}

M - mean; SD - standard deviation; $1 \mathrm{~mm} \mathrm{Hg}=133.3 \mathrm{~Pa}$.

${ }^{a}$ Patient age at the time of the test.

${ }^{\mathrm{b}}$ As a proper control of hypertension have been assumed: average pressure during $24 \mathrm{~h}-130 / 80 \mathrm{~mm} \mathrm{Hg}$, during the day - 135/85 mm Hg, during the night $-120 / 70 \mathrm{~mm} \mathrm{Hg}$.

${ }^{c} \mathrm{p}<0.05$ vs. $<50$ years.

${ }^{\mathrm{d}} \mathrm{p}<0.05$ vs. $50-65$ years (at Fisher's exact test).

Table 2. Statistical analysis of the weather condition influence on the blood pressure of the study population with arterial hypertension

\begin{tabular}{|c|c|c|c|}
\hline \multirow{2}{*}{ Season and blood pressure } & \multicolumn{2}{|c|}{ Group } & \multirow{2}{*}{$\mathrm{p}$} \\
\hline & $\mathrm{A}$ & $\mathrm{B}$ & \\
\hline \multicolumn{4}{|l|}{ All seasons } \\
\hline patients [n] & 834 & 828 & \\
\hline \multicolumn{4}{|l|}{ day blood pressure $[\mathrm{mm} \mathrm{Hg}](\mathrm{M} \pm \mathrm{SD})$} \\
\hline systolic & $121.18 \pm 14.12$ & $121.05 \pm 13.04$ & 0.693 \\
\hline diastolic & $69.20 \pm 10.43$ & $68.73 \pm 9.90$ & 0.446 \\
\hline \multicolumn{4}{|l|}{ night blood pressure $[\mathrm{mm} \mathrm{Hg}](\mathrm{M} \pm \mathrm{SD})$} \\
\hline systolic & $109.58 \pm 14.63$ & $109.64 \pm 14.74$ & 0.980 \\
\hline diastolic & $58.48 \pm 8.35$ & $59.27 \pm 9.04$ & 0.229 \\
\hline
\end{tabular}


Table 2. Statistical analysis of the weather condition influence on the blood pressure of the study population with arterial hypertension - cont.

\begin{tabular}{|c|c|c|c|}
\hline \multirow{2}{*}{ Season and blood pressure } & \multicolumn{2}{|c|}{ Group } & \multirow{2}{*}{$\mathrm{p}$} \\
\hline & A & B & \\
\hline \multicolumn{4}{|l|}{ Spring } \\
\hline patients [n] & 204 & 250 & \\
\hline \multicolumn{4}{|l|}{ day blood pressure $[\mathrm{mm} \mathrm{Hg}](\mathrm{M} \pm \mathrm{SD})$} \\
\hline systolic & $123.40 \pm 14.08$ & $121.25 \pm 14.01$ & 0.043 \\
\hline diastolic & $71.42 \pm 10.65$ & $68.75 \pm 9.86$ & 0.005 \\
\hline \multicolumn{4}{|l|}{ night blood pressure $[\mathrm{mm} \mathrm{Hg}](\mathrm{M} \pm \mathrm{SD})$} \\
\hline systolic & $108.93 \pm 13.54$ & $109.89 \pm 16.01$ & 0.854 \\
\hline diastolic & $58.64 \pm 8.28$ & $59.05 \pm 8.81$ & 0.592 \\
\hline \multicolumn{4}{|l|}{ Summer } \\
\hline patients [n] & 186 & 161 & \\
\hline \multicolumn{4}{|l|}{ day blood pressure $[\mathrm{mm} \mathrm{Hg}](\mathrm{M} \pm \mathrm{SD})$} \\
\hline systolic & $120.33 \pm 12.94$ & $120.94 \pm 13.28$ & 0.802 \\
\hline diastolic & $68.89 \pm 10.07$ & $69.45 \pm 10.74$ & 0.628 \\
\hline \multicolumn{4}{|l|}{ night blood pressure $[\mathrm{mm} \mathrm{Hg}](\mathrm{M} \pm \mathrm{SD})$} \\
\hline systolic & $110.96 \pm 16.25$ & $109.55 \pm 14.19$ & 0.627 \\
\hline diastolic & $59.90 \pm 10.58$ & $59.41 \pm 8.34$ & 0.838 \\
\hline \multicolumn{4}{|l|}{ Autumn } \\
\hline patients [n] & 223 & 213 & \\
\hline \multicolumn{4}{|l|}{ day blood pressure $[\mathrm{mm} \mathrm{Hg}](\mathrm{M} \pm \mathrm{SD})$} \\
\hline systolic & $121.71 \pm 14.33$ & $120.79 \pm 13.81$ & 0.289 \\
\hline diastolic & $69.93 \pm 10.82$ & $68.63 \pm 9.50$ & 0.218 \\
\hline \multicolumn{4}{|l|}{ night blood pressure $[\mathrm{mm} \mathrm{Hg}](\mathrm{M} \pm \mathrm{SD})$} \\
\hline systolic & $110.28 \pm 15.17$ & $111.52 \pm 15.29$ & 0.304 \\
\hline diastolic & $59.52 \pm 8.74$ & $59.52 \pm 9.39$ & 0.831 \\
\hline \multicolumn{4}{|l|}{ Winter } \\
\hline patients $[\mathrm{n}]$ & 232 & 193 & \\
\hline \multicolumn{4}{|l|}{ day blood pressure $[\mathrm{mm} \mathrm{Hg}](\mathrm{M} \pm \mathrm{SD})$} \\
\hline systolic & $121.40 \pm 14.81$ & $120.82 \pm 13.29$ & 0.722 \\
\hline diastolic & $69.62 \pm 10.78$ & $69.51 \pm 10.33$ & 0.882 \\
\hline \multicolumn{4}{|l|}{ night blood pressure $[\mathrm{mm} \mathrm{Hg}](\mathrm{M} \pm \mathrm{SD})$} \\
\hline systolic & $110.90 \pm 15.66$ & $106.82 \pm 12.73$ & 0.013 \\
\hline diastolic & $58.70 \pm 8.30$ & $58.48 \pm 8.23$ & 0.991 \\
\hline
\end{tabular}

A - group included 50\% of the days/nights with a lower average value of atmospheric pressure; B - group included 50\% of the days/nights with a higher average atmospheric pressure.

Other abbreviations as in Table 1. 
the air-conditioned rooms. This reduces the influence of many weather factors: temperature, humidity, wind speed and direction, and sunlight. However, this does not refer to the influence of AP.

Atmospheric pressure, particularly in combination with other weather stimuli, influences the autonomic and endocrine systems. It has been commonly observed that the decrease in AP reduces blood oxygenation. Reduced saturation leads to activation of the autonomic nervous and the endocrine systems and, consequently, to an increase in BP [7]. Some studies have confirmed the inverse relationship between AP and arterial BP [17,18]. Observations from the mentioned above research revealed a similar relationship between AP and BP limited mainly to the spring and winter months same like in our study. The patients, whose measurements were taken during the days with lower atmospheric pressure, had significantly higher BP compared to the patients whose measurements were taken during the days with higher atmospheric pressure.

Low atmospheric pressure is also reflected in an increase in the incidence of diseases, for which hypertension constitutes a part of pathogenesis. This relationship is related to the cardiovascular system diseases [19-23]. Among cerebrovascular events, low atmospheric pressure is associated with an increase in the risk of haemorrhagic stroke and subarachnoid haemorrhage [21-23]. It is speculated that changes in atmospheric pressure may lead to changes in pressure within the vessel wall and facilitate its rupture, especially in an aneurysmatic modified vessel [22]. Rupture of an aneurysm is facilitated by either an increase in BP inside the vessel or the rise of intramural pressure due to a decrease in intracranial pressure. Both situations might be associated with a decrease in atmospheric pressure.

In the case of this study, the influence of barometric pressure on BP of the patients was limited to the spring and pre-spring (winter) months. In the moderate climate of Poland, variations of the weather are the highest in this period. In March, low atmospheric pressure fronts are frequently observed. Between 2009 and 2012, when the study was conducted, most sudden changes in barometric pressure occurred during winter months and early spring, especially in March. Spring and pre-spring seasons in Polish climate constitute a period between barometrically unstable winter and stable summer; therefore, its bioclimatic, negative influence on the results is sound. In the past, the fatigue of the human body after winter season was commonly observed due to lack of fresh food and limited food supply.

In Polish culture there are many common proverbs associated with the difficulty of maintaining healthy lifestyle during the winter/spring seasons. Development of civilization, especially inventions of home heating systems, air conditioning or global transportation, has also contributed to the weakening of natural human adaptative mechanisms. This can be correlated with additional health issues such as the weather stress [24], or even psychological stress, which, according to the Takashima Stroke Registry, has been measured by the increase of BP related strokes during spring months [23].

As early as in 1961 in a letter from Rose to the "Nature Journal," it was mentioned that BP of patients was increased during spring and late summer, as observed on a 56-year old patient diagnosed with ischemic heart disease [25]. A similar problem has been also studied by Hozawa, who has examined a group of 97 voluntaries and observed increased BP levels in March comparing to other months of the year [26]. There are also other works mentioning the influence of the winter/summer season on the number of strokes and heart attacks [23,27].

Our results emphasize the impact of decreasing atmospheric pressure on the growth of systolic BP in the winter nights. In many previous studies, an increased risk of cardio- and cerebrovascular events in winter [26,28-31] has been observed. It is also known from everyday practice that these events happened usually at night. Their relationship with arterial hypertension was explained by low outdoor or indoor temperature in climatic context $[16,26,32,33]$. 
Our findings demand further studies, which will help to explain the issue of influence of atmospheric pressure on blood pressure.

The second limitation of the study is the fact that during the statistical analysis, only arterial pressure was taken into account. It means that any other ailments that the patients may have been suffering from were omitted due to the lack of patient data. Also, pharmacological treatments, that these patients may have been undergoing, could have affected the analyzed data.

Similarly, no data was provided concerning patients' habits, e.g., smoking or alcohol abuse. It would be helpful to know the exact time when a patient was exposed to any additional substances (such as alcohol). These data could modify the research results (as covered in [34]). Other missing data may include, e.g., physical activity, time of each meal and stressful situations the patients were exposed to at the time of the study.

Another important factor impacting the results was the limitation of the measuring station itself, which did not take into account the amount of rainfall and lightning, which can also have influence on human health. In addition, properties of the moderate climate of central Poland, which is characterized by frequent but mild weather changes, provide a difficult boilerplate to base this examination on.

The mentioned above limitations should be taken into account when planning any further studies on this subject. In addition, a chronopharmacologic analysis during evaluation of the patients' cardiovascular system parameters could strengthen credibility of the obtained results, especially if it was conducted on the same group of patients.

The analysis indicated a significant difference in BP recorded during low atmospheric pressure compared to BP recorded during higher atmospheric pressure in the spring. A similar relationship was noticed for systolic BP in the winter nights. In these seasons, clinicians should pay particular attention to BP control because of a risk of cardio- and cerebrovascular events, which has been reported in the previous studies.

In other seasons of the year, no statistically significant correlation between atmospheric pressure and BP was observed.

\section{CONCLUSIONS}

The study confirmed an inverse relationship between atmospheric pressure and blood pressure during the spring days, and systolic blood pressure during winter nights. Therefore, it is advisable to pay closer attention to blood pressure control during these periods - especially when we take into account the fact that arterial pressure fluctuations may lead to an increased risk of cardiovascular events.

\section{REFERENCES}

1. Hippocrate, Cornarius. [On airs, waters, and places]. Apud Johannem Elsevirium; 1658. Latin.

2. Yackerson NS, Bromberg L, Adler B, Aizenberg A. Possible effects of changes in the meteorological state over semi-arid areas on the general well-being of weather-sensitive patients. Environ Health. 2012;11:26, http://dx.doi.org/10.1186/1476069X-11-26.

3. Morabito M, Crisci A, Orlandini S, Maracchi G, Gensini GF, Modesti PA. A synoptic approach to weather conditions discloses a relationship with ambulatory blood pressure in hypertensives. Am J Hypertens. 2008;21:748-52, http://dx.doi. org/10.1038/ajh.2008.177.

4. Ishikawa K, Niwa M, Tanaka T. Difference of intensity and disparity in impact of climate on several vascular diseases. Heart Vessels. 2012;27:1-9, http://dx.doi.org/10.1007/s00380011-0206-5.

5. Petersen WF. The patient and the weather. Ann Arbor: Edwards Brothers, Inc.; 1935.

6. Von Mackensen S, Hoeppe P, Maarouf A, Tourigny P, Nowak D. Prevalence of weather sensitivity in Germany and Canada. Int J Biometeorol. 2005;49:156-66, http://dx.doi. org/10.1007/s00484-004-0226-2. 
7. Pope CA, Dockery DW, Kanner RE, Villegas GM, Schwartz J. Oxygen saturation, pulse rate, and particulate air pollution: A daily time-series panel study. Am J Respir Crit Care Med. 1999;159:365-72, http://dx.doi.org/10.1164/ ajrccm.159.2.9702103.

8. Mancia G, Fagard R, Narkiewicz K, Redón J, Zanchetti A, Böhm M, et al. 2013 ESH/ESC guidelines for the management of arterial hypertension: The task force for the management of arterial hypertension of the European Society of Hypertension (ESH) and of the European Society of Cardiology (ESC). J Hypertens. 2013;31:1281-357, http://dx.doi. org/10.1097/01.hjh.0000431740.32696.cc.

9. O'Brien E, Mee F, Atkins N, O'Malley K. Accuracy of the SpaceLabs 90207 determined by the British Hypertension Society protocol. J Hypertens. 1991;9:573-4, http://dx.doi. org/10.1097/00004872-199106000-00016.

10. Certificate of authentication [Internet]. Reguły: LAB-EL; 1996-2015 [cited 2014 Oct 20]. Available from: http://www. label.pl/img/switwl.jpg.

11. Woś A. [The climate of Poland]. Warszawa: Wydawnictwo Naukowe PWN; 1999. Polish.

12. Lorenc H. [The climate atlas of Poland]. Warszawa: Instytut Meteorologii i Gospodarki Wodnej; 2005. Polish.

13. Modesti PA, Morabito M, Bertolozzi I, Massetti L, Panci G, Lumachi $\mathrm{C}$, et al. Weather-related changes in 24-hour blood pressure profile: Effects of age and implications for hypertension management. Hypertension. 2006;47:155-61, http:// dx.doi.org/10.1161/01.HYP.0000199192.17126.d4.

14. Modesti PA, Morabito M, Massetti L, Rapi S, Orlandini S, Mancia G, et al. Seasonal blood pressure changes: An independent relationship with temperature and daylight hours. Hypertension. 2013;61:908-14, http://dx.doi.org/10.1161/ HYPERTENSIONAHA.111.00315.

15. Jehn M, Appel LJ, Sacks FM, Miller ER 3rd for the DASH Collaborative Research Group. The effect of ambient temperature and barometric pressure on ambulatory blood pressure variability. Am J Hypertens. 2002;15:941-5, http:// dx.doi.org/10.1016/S0895-7061(02)02999-0.
16. Lewington S, Li L, Sherliker P, Guo Y, Millwood I, Bian Z, et al. Seasonal variation in blood pressure and its relationship with outdoor temperature in 10 diverse regions of China: The China Kadoorie Biobank. J Hypertens. 2012;30:138391, http://dx.doi.org/10.1097/HJH.0b013e32835465b5.

17. Skrobowski A. [The impact of selected atmospheric conditions on blood pressure]. Warszawa: Wojskowa Akademia Medyczna; 1998. Polish.

18. Weinbacher M, Martina B, Bart T, Drewe J, Gasser P, Gyr K. Blood pressure and atmospheric pressure. Ann N Y Acad Sci. 1996;783:335-6, http://dx.doi.org/10.1111/j.1749-6632.1996. tb26737.x.

19. Sarna S, Romo M, Siltanen P. Myocardial infarction and weather. Ann Clin Res. 1977;9:222-32.

20. Danet S, Richard F, Montaye M, Beauchant S, Lemaire B, Graux $\mathrm{C}$, et al. Unhealthy effects of atmospheric temperature and pressure on the occurrence of myocardial infarction and coronary deaths. A 10-year survey: The LilleWorld Health Organization MONICA project (Monitoring trends and determinants in cardiovascular disease). Circulation. 1999;100:1-7, http://dx.doi.org/10.1161/01. CIR.100.1.e1.

21. Dawson J, Weir C, Wright F, Bryden C, Aslanyan S, Lees K, et al. Associations between meteorological variables and acute stroke hospital admissions in the west of Scotland. Acta Neurol Scand. 2008;117:85-9.

22. Law HY, Wong GK, Chan DT, Wong L, Poon WS. Meteorological factors and aneurysmal subarachnoid haemorrhage in Hong Kong. Hong Kong Med J. 2009;15:85-9.

23. Turin TC, Kita Y, Murakami Y, Rumana N, Sugihara H, Morita $\mathrm{Y}$, et al. Higher stroke incidence in the spring season regardless of conventional risk factors: Takashima Stroke Registry, Japan, 1988-2001. Stroke. 2008;39:745-52, http:// dx.doi.org/10.1161/STROKEAHA.107.495929.

24. Hessman-Kosaris A. [The impact of weather on mood]. Warszawa: Diogenes; 1998. Polish.

25. Rose G. Seasonal variation in blood pressure in man. Nature. 1961;189:235, http://dx.doi.org/10.1038/189235a0. 
26. Hozawa A, Kuriyama S, Shimazu T, Ohmori-Matsuda K, Tsuji I. Seasonal variation in home blood pressure measurements and relation to outside temperature in Japan. Clin Exp Hypertens. 2011;33:153-8, http://dx.doi.org/10.3109/10 641963.2010 .531841$.

27. Kriszbacher I, Czopf L, Bódis J. The effects of seasonal variations and weather conditions on the occurrence of heart attacks in Hungary between 2000-2004. Orv Hetil. 2007;148:731-6, http://dx.doi.org/10.1556/OH.2007.27980.

28. Minami J, Kawano Y, Ishimitsu T, Yoshimi H, Takishita S. Seasonal variations in office, home and $24 \mathrm{~h}$ ambulatory blood pressure in patients with essential hypertension. J Hypertens. 1996;14:1421-5, http://dx.doi.org/10.1097/00004872199612000-00006.

29. Sega R, Cesana G, Bombelli M, Grassi G, Stella ML, Zanchetti A, et al. Seasonal variations in home and ambulatory blood pressure in the PAMELA population. J Hypertens. 1998;16:1585-92, http://dx.doi.org/10.1097/00004872199816110-00004.

30. Rumana N, Kita Y, Turin TC, Murakami Y, Sugihara H, Morita Y, et al. Seasonal pattern of incidence and case fatality of acute myocardial infarction in a Japanese population (from the Takashima AMI Registry, 1988 to 2003). Am J Cardiol. 2008;102:1307-11, http://dx.doi.org/10.1016/j.amjcard.2008.07.005.

31. Shinkawa A, Ueda K, Hasuo Y, Kiyohara Y, Fujishima M. Seasonal variation in stroke incidence in Hisayama, Japan. Stroke. 1990;21:1262-7, http://dx.doi.org/10.1161/01. STR.21.9.1262.

32. Saeki K, Obayashi K, Iwamoto J, Tone N, Okamoto N, Tomioka K, et al. Stronger association of indoor temperature than outdoor temperature with blood pressure in colder months. J Hypertens. 2014;32:1582-9, http://dx.doi. org/10.1097/HJH.0000000000000232.

33. Woodhouse PR, Khaw KT, Plummer M. Seasonal variation of blood pressure and its relationship to ambient temperature in an elderly population. J Hypertens. 1993;11:1267-74, http://dx.doi.org/10.1097/00004872-199311000-00015.

34. Kristal-Boneh E, Harari G, Green MS. Seasonal change in 24-hour blood pressure and heart rate is greater among smokers than nonsmokers. Hypertension. 1997;30:436-41, http://dx.doi.org/10.1161/01.HYP.30.3.436.

This work is available in Open Access model and licensed under a Creative Commons Attribution-NonCommercial 3.0 Poland License - http://creativecommons.org/ licenses/by-nc/3.0/pl/deed.en. 